\title{
Elevated gradient after mitral valve repair: The effect of surgical technique and relevance of postoperative atrial fibrillation
}

\author{
Wenrui Ma, MD, ${ }^{\text {a,b }}$ Wei Shi, MD, ${ }^{\text {a }}$ Weihua Wu, MD, ${ }^{\mathrm{c}}$ Wei Ye, MD, ${ }^{\mathrm{a}}$ Ye Kong, MD, PhD, ${ }^{\mathrm{a}}$ \\ Dan Zhu, MD, $\mathrm{PhD}$, ${ }^{\mathrm{a}}$ and Wei Zhang, $\mathrm{MD}^{\mathrm{a}}$
}

\section{ABSTRACT}

Objectives: We sought to investigate the effect of surgical technique in mitral valve repair on postoperative transmitral gradient (PTMG) and the relationship between PTMG and postoperative atrial fibrillation (AF).

Methods: In this retrospective study, 390 patients who underwent mitral valve repair for degenerative mitral regurgitation without AF were included. PTMG was measured using transthoracic echocardiography before patient discharge. At follow-up, occurrences of AF within 6 months of surgery (early AF) and 6 months after surgery (late AF), as well as clinical and echocardiographic data were documented and investigated.

Results: The in-hospital mortality was 0 , and the mean gradient was $3.1 \pm 1.2 \mathrm{~mm}$ $\mathrm{Hg}$ before patient discharge. The risks for higher PTMG included cleft closure, edge-to-edge technique, full ring annuloplasty, and smaller indexed prosthetic size $(P<.05$ for all). After a median follow-up of 46 months, stable sinus rhythm was maintained in $73.1 \%$ of the overall cohort and early AF occurred in $22.7 \%$ of patients. A total of 32 patients $(8.5 \%)$ had late AF, which was significantly associated with PTMG (odds ratio, 3.93; $P=.004$ ). The minimum $P$ value approach identified a mean gradient of $\geq 4.5 \mathrm{~mm} \mathrm{Hg}$ as the best threshold for predicting late $\mathrm{AF}\left(\chi^{2}=40.704 ; P<.001\right)$.

Conclusions: Patients who undergo mitral valve repair for degenerative mitral insufficiency might benefit from modification of the existing leaflet repair and annuloplasty techniques to achieve a lower PTMG level, which is associated with a decreased incidence of late AF during midterm follow-up. (J Thorac Cardiovasc Surg 2019;157:921-27)

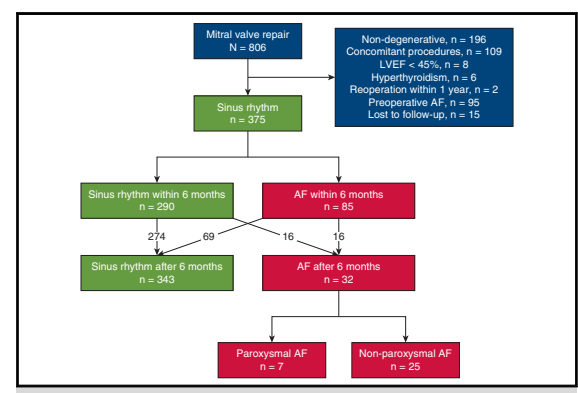

Rhythm outcomes after mitral valve repair for degenerative mitral regurgitation.

\section{Central Message}

Affected by leaflet repair and annuloplasty, a transmitral gradient $>4.5 \mathrm{~mm} \mathrm{Hg}$ is associated with postoperative atrial fibrillation.

\section{Perspective}

With advances in mitral valve repair techniques, a reduced orifice area and an elevated gradient have become a matter of concern. In this study we verified the relationship between transmitral gradient and atrial fibrillation during midterm follow-up. Our findings may be applied in further modification of repair techniques, namely calculating the minimum ring size on the basis of orifice area before surgery.

See Commentaries on pages 928 and 930.

\footnotetext{
From the ${ }^{\mathrm{a}}$ Departments of Cardiovascular Surgery, and ${ }^{\mathrm{c}}$ Echocardiography, Shanghai Chest Hospital, Shanghai Jiao Tong University, Shanghai, China; and ${ }^{\mathrm{b}}$ Department of Cardiac Surgery, Zhongshan Hospital, Fudan University, Shanghai, China.

This study was supported by the National Natural Science Foundation of China (81770385 to Dr Zhu) and 2 institutional grants from Shanghai Chest Hospital (2014YZDH10302 and YZ2015-ZX03 to Dr Zhang).

Drs Ma and Shi contributed equally to this work.

Received for publication April 13, 2018; revisions received July 7, 2018; accepted for publication July 23, 2018; available ahead of print Oct 29, 2018.

Addresses for reprints: Dan Zhu, MD, PhD, Department of Cardiovascular Surgery, Shanghai Chest Hospital, Shanghai Jiao Tong University, No 241 Huaihaixi Rd, 200030 Shanghai, China (E-mail: zhudanmd@163.com). or Wei Zhang, MD, Department of Cardiovascular Surgery, Shanghai Chest Hospital, Shanghai Jiao Tong University, No. 241 Huaihaixi Rd, 200030 Shanghai, China (E-mail: zhangwyyy@hotmail.com).

$0022-5223 / \$ 36.00$

Copyright (c) 2018 by The American Association for Thoracic Surgery

https://doi.org/10.1016/j.jtcvs.2018.07.107
}

Mitral valve repair is a standard procedure in treatment of significant degenerative mitral regurgitation (MR), with better survival rates and cardiac reverse remodeling compared with valve replacement. ${ }^{1}$ Although numerous studies have extensively investigated the risks for mortality, morbidity, and durability of repair after surgery, reports regarding the effect of postoperative transmitral gradient (PTMG) on clinical

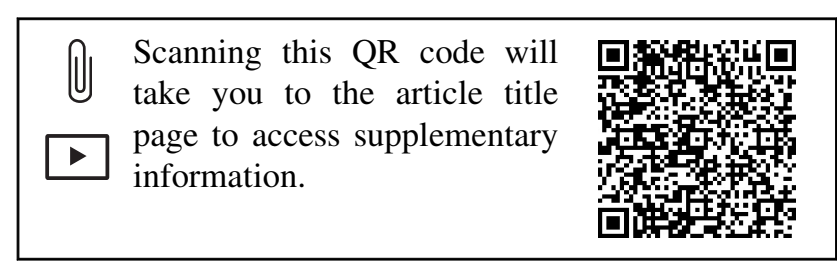




$$
\begin{aligned}
& \text { Abbreviations and Acronyms } \\
& \text { AF }=\text { atrial fibrillation } \\
& \text { CI }=\text { confidence interval } \\
& \text { LVEF }=\text { left ventricular ejection fraction } \\
& \text { MG }=\text { mean gradient } \\
& \text { MR }=\text { mitral regurgitation } \\
& \text { OR }=\text { odds ratio } \\
& \text { PTMG } \\
& \text { TEE }=\text { postoperative transmitral gradient } \\
&
\end{aligned}
$$

outcomes are less frequent. Chan and colleagues reported that a mean gradient $(\mathrm{MG})>3 \mathrm{~mm} \mathrm{Hg}$ was associated with lower exercise capacity and worse quality of life. ${ }^{2}$ Incidence of adverse events, namely atrial fibrillation (AF), might also be increased by an elevated PTMG. However, this relationship and an appropriate threshold of PTMG predictive of postoperative AF have not been studied. Therefore, the aims of this study were to identify surgical techniques that lead to an elevated PTMG after mitral valve repair and to evaluate the relevance of PTMG in patients with postoperative AF during follow-up.

\section{METHODS \\ Patient Selection}

The study was reviewed by the Ethics Committee of Patients of Shanghai Chest Hospital. The requirement for informed consent was waived because of the retrospective nature of the study (date and number of institutional review board approval: January 18, 2018; KY18003). Between January 2006 and January 2016, 806 consecutive patients at our institution underwent a surgical mitral valve repair for significant MR. Exclusion criteria were as follows: (1) nondegenerative MR, including rheumatic, ischemic, congenital, or infective MR $(n=196)$; (2) concomitant other valve replacement, aortic surgery, or coronary artery bypass grafting ( $\mathrm{n}=109$ ); (3) left ventricular ejection fraction (LVEF) $<45 \%$ to exclude the combined functional mitral pathology $(n=8)$; (4) hyperthyroidism $(n=6)$; (5) mitral valve reoperation within 1 year because of surgical failure $(\mathrm{n}=2)$; and $(6)$ preoperative $\mathrm{AF}$, including paroxysmal, persistent, and long-persistent AF $(\mathrm{n}=95)$. After screening, 390 patients were included in this study. The patient characteristics and operative data of the overall cohort are shown in Table 1.

\section{Surgical Techniques and Perioperative Management}

Operations were performed through a median sternotomy $(n=351)$, a ministernotomy $(n=11)$, or a right minithoracotomy $(n=28)$, with the use of mild hypothermic cardiopulmonary bypass and intermittent antegrade cold blood cardioplegia. The structural characteristics of the entire mitral complex and its pathology were identified using nerve hooks and saline injections. The choice of repair technique was determined according to the surgeon's preference. The details of the leaflet repair techniques used in the cohort, including leaflet resection (quadrangular or triangular), neochordal replacement (including loop-in-loop technique), edge-to-edge technique, commissuroplasty, and leaflet plication, were described in our previous work. ${ }^{3}$ In the present study's cohort, 4 types of annuloplasty rings were implanted: 2 flexible C-shape bands (Cosgrove band from Edwards Lifesciences, Irving, Calif, and Sovering band from Sorin Biomedica Cardio S.r.l., Saluggia, Italy) and 2 semirigid full rings (Carpentier-Edwards Physio I ring from Edwards Lifesciences and Sorin Memo-3D ring from
TABLE 1. Baseline characteristics (overall cohort, $\mathbf{N}=390$ )

\begin{tabular}{lc}
\hline \multicolumn{1}{c}{ Characteristic } & Value \\
\hline Age, $\mathrm{y}$ & $52.7 \pm 12.2$ \\
\hline Male sex & $251(64.4)$ \\
\hline Body surface area, ${ }^{2}$ & $1.67 \pm 0.23$ \\
NYHA functional class III to IV & $148(37.9)$ \\
Comorbidities & \\
Hypertension & $115(29.5)$ \\
Diabetes mellitus & $18(4.6)$ \\
Coronary artery disease & $32(8.2)$ \\
Chronic obstructive pulmonary disease & $4(1.0)$ \\
Chronic kidney disease & $3(0.8)$ \\
History of stroke & $7(1.8)$ \\
Transthoracic echocardiography & \\
Left atrial diameter, mm & $43.7 \pm 6.6$ \\
Left ventricular end-systolic diameter, $\mathrm{mm}$ & $33.9 \pm 5.3$ \\
Left ventricular end-diastolic diameter, $\mathrm{mm}$ & $57.0 \pm 6.6$ \\
LVEF, \% & $63.7 \pm 4.4$ \\
Systolic pulmonary artery pressure, $\mathrm{mm} \mathrm{Hg}$ & $44.3 \pm 14.6$ \\
\hline Col
\end{tabular}

Continuous variables are presented as mean \pm SD and categorical variables as $\mathrm{n}(\%)$. NYHA, New York Heart Association; $L V E F$, left ventricular ejection fraction.

Sorin Biomedica Cardio S.r.1.). The choice of prosthetic type was according to the surgeon's preference. The prosthetic size was determined according to the measurement of intertrigonal distance or anterior leaflet area. Postbypass transesophageal echocardiography (TEE) was not performed until mean arterial pressure reached $75 \mathrm{~mm} \mathrm{Hg}$ with adequate left ventricular filling. A second repair attempt was considered if TEE detected greater than a mild degree of residual MR, mitral stenosis ( $\mathrm{MG}>6 \mathrm{~mm} \mathrm{Hg}$ ), or systolic anterior motion that could not be resolved by discontinuation of inotropic agents, heart rate control, and volume management. ${ }^{4}$ Concomitant procedures were limited to tricuspid ring annuloplasty $(n=61)$.

The heart rhythm of each patient was monitored continuously from postoperative day 0 until patient discharge using telemetry or a monitoring device. Whenever a period of AF or atrial flutter that lasted more than 30 seconds was noted by either the nursing staff or the monitoring device, the operating surgeon or a physician on-call would be informed. The data on episodes of AF or atrial flutter and their treatment, including use of class I and/or III antiarrhythmic drugs, $\beta$-blockers, calcium channel blockers, and electrical cardioversion, were collected by reviewing records of daily rounds, order lists, and nursing notes. Unless contraindicated, patients with perioperative AF were discharged with warfarin and class I or III antiarrhythmic drugs. Typically, we did not use prophylactic antiarrhythmic drugs for patients without $\mathrm{AF}$ before discharge. $\beta$-Blockers or calcium channel blockers were not considered to be antiarrhythmic drugs.

Transthoracic echocardiography was performed on all subjects before discharge. MGs were calculated using the modified Bernoulli equation at a heart rate ranging from 50 to 100 beats per minute. Echocardiograms performed during tachycardia were excluded from analysis.

\section{Follow-up}

Routine follow-up included an electrocardiogram, 24-hour Holter monitoring, or pacemaker interrogation, and was performed at the discretion of the operating surgeon or referring cardiologist. Specifically, electrocardiogram or pacemaker interrogation was routinely performed at 3,6 , and 12 months after surgery, and yearly thereafter. Patients with early $\mathrm{AF}$ and those who complained of paroxysmal/continuous palpitations received 24-hour Holter monitoring. Holter monitoring was repeated if the complaints persisted, even if previous reports were normal. Antiarrhythmic drugs and warfarin were withdrawn 6 months after surgery, 
provided sinus rhythm was restored. Electrical cardioversion and transcatheter ablation were considered in patients with AF beyond the first 6 months after surgery. Practices of clinical evaluation, rhythm monitoring, and medical/interventional management of $\mathrm{AF}$ were on the basis of the current guidelines. ${ }^{5}$ Moreover, clinical cardiac function, degree of residual MR, MG, and other echocardiographic parameters were also evaluated during outpatient visits. The echocardiographic data before discharge and during follow-up are listed in Table 2.

\section{End Points}

In this study, early AF was defined as occurrence of AF or atrial flutter $>30$ seconds within 6 months after surgery (from postoperative day 0 to day 180 ), assessed using telemetry throughout hospitalization, electrocardiogram, 24-hour Holter monitoring, or pacemaker interrogation. Similarly, AF or atrial flutter that occurred or lasted beyond the first 6 months after surgery was considered late AF. The patients with no sign of early or late AF throughout the duration of their follow-up were considered to be in stable sinus rhythm. The end points of this study were all-cause mortality and incidence of early and late AF.

\section{Statistical Analysis}

Continuous variables are presented as mean \pm SD and were compared using the Student $t$ test or Mann-Whitney $U$ test. Categorical variables are presented as numbers and percentages and were compared using the $\chi^{2}$ test or Fisher exact test. The Kaplan-Meier technique was used to evaluate 5-year survival.

Using empirical evidence, we hypothesized that an optimal MG after mitral valve repair should be no higher than $3 \mathrm{~mm} \mathrm{Hg} .{ }^{2}$ On the basis of that premise, the forward stepwise multivariate logistic regression models were used to identify significant factors that led to $\mathrm{MG}>3 \mathrm{~mm} \mathrm{Hg}$ $\left(P_{\text {entry }}=.05, P_{\text {stay }}=.05\right)$. The following preoperative and operative covariates were included in the model: age older than 65 years, sex, operating surgeon, left atrial diameter, left ventricular end-systolic and enddiastolic diameters, LVEF, type of incision, location of degenerative lesion, leaflet resection, quadrangular resection, sliding technique, neochordal replacement, loop-in-loop technique, edge-to-edge technique, commissuroplasty, leaflet plication, type of annuloplasty ring, indexed prosthetic size, and tricuspid annuloplasty. The final model's goodness of fit was assessed with the Hosmer-Lemeshow statistic. Similarly, apart from the aforementioned covariates, baseline comorbidities, New York Heart Association functional class, medications at discharge, postoperative echocardiographic parameters, and cardiac rhythm were also entered into multivariate logistic regression models to determine independent predictors for early and late AF. Additionally, a minimum $P$ value approach was used for the threshold value of MG that independently predicted the incidence of late AF. ${ }^{6}$ In this approach, the dichotomization of MG was performed at an interval of $0.5 \mathrm{~mm} \mathrm{Hg}$. Each time, a $2 \times 2$ contingency table with late $\mathrm{AF}$ and dichotomized MG was created (eg, $<2 \mathrm{~mm} \mathrm{Hg}$ vs $\geq 2 \mathrm{~mm} \mathrm{Hg} ;<2.5 \mathrm{~mm} \mathrm{Hg}$ vs $\geq 2.5 \mathrm{~mm} \mathrm{Hg}$, etc). The cutoff value for MG that had the maximum $\chi^{2}$ statistic was selected as the threshold that best predicted late AF. Finally, a threshold of indexed orifice area of full annuloplasty ring for predicting the MG threshold for late AF was calculated in a similar manner, using an interval of $0.25 \mathrm{~cm}^{2} / \mathrm{m}^{2}$ for dichotomization. Areas of C-shape bands were unavailable because of their open structure. In this study, prosthetic sizes and orifice areas were indexed according to body surface area.

A 2-tailed $P$ value $<.05$ was considered statistically significant. All statistical analyses were performed using SAS version 9.2 (IBM Corp, Armonk, NY) and OriginPro 2018 (OriginLab, Northampton, Mass) software.

\section{RESULTS}

\section{Patient Characteristics and Perioperative Data}

The mean age was $52.7 \pm 12.2$ years, with a male predominance $(64.4 \%)$ in the overall cohort. A total of 148
TABLE 2. Transthoracic echocardiography before discharge and at early and late follow-ups

\begin{tabular}{|c|c|c|c|}
\hline Characteristic & $\begin{array}{c}\text { Before } \\
\text { discharge } \\
(\mathbf{N}=\mathbf{3 9 0})\end{array}$ & $\begin{array}{l}\text { At 6-month } \\
\text { follow-up } \\
(\mathrm{n}=375)\end{array}$ & $\begin{array}{c}\text { At late } \\
\text { follow-up } \\
(n=375)\end{array}$ \\
\hline \multicolumn{4}{|l|}{ Residual MR } \\
\hline None & $197(50.5)$ & $148(39.5)$ & 127 (33.9) \\
\hline Trivial & $159(40.8)$ & $156(41.6)$ & $165(44.0)$ \\
\hline Mild & $34(8.7)$ & $66(17.6)$ & $61(16.3)$ \\
\hline Moderate or severe & $0(0)$ & $5(1.3)$ & $22(5.9)$ \\
\hline MG, mm Hg & $3.1 \pm 1.2$ & $3.3 \pm 1.2$ & $3.3 \pm 1.4$ \\
\hline Left atrial diameter, $\mathrm{mm}$ & $36.1 \pm 5.7$ & $38.1 \pm 7.2$ & $38.9 \pm 6.2$ \\
\hline $\begin{array}{l}\text { Left ventricular end-systolic } \\
\text { diameter, } \mathrm{mm}\end{array}$ & $31.6 \pm 5.9$ & $31.0 \pm 5.1$ & $30.7 \pm 5.8$ \\
\hline $\begin{array}{l}\text { Left ventricular end-diastolic } \\
\text { diameter, } \mathrm{mm}\end{array}$ & $48.9 \pm 6.0$ & $49.3 \pm 5.4$ & $48.7 \pm 5.4$ \\
\hline LVEF, \% & $59.8 \pm 5.7$ & $60.7 \pm 5.1$ & $61.8 \pm 5.5$ \\
\hline $\begin{array}{l}\text { Systolic pulmonary artery } \\
\text { pressure, } \mathrm{mm} \mathrm{Hg}\end{array}$ & $33.3 \pm 5.3$ & $36.1 \pm 8.6$ & $36.8 \pm 10.1$ \\
\hline $\begin{array}{l}\text { Tricuspid regurgitation, } \\
\text { degree }\end{array}$ & $1.0 \pm 0.8$ & $1.0 \pm 0.8$ & $1.1 \pm 0.9$ \\
\hline
\end{tabular}

Continuous variables are presented as mean \pm SD and categorical variables as $\mathrm{n}(\%)$ $M R$, Mitral regurgitation; $M G$, mean gradient; $L V E F$, left ventricular ejection fraction.

patients $(37.9 \%)$ were designated as New York Heart Association functional class III-IV.

The mean cardiopulmonary bypass and aortic cross-clamp times were $119.7 \pm 35.9$ minutes and $80.6 \pm 24.7$ minutes, respectively. Anterior leaflet prolapse was identified in 87 patients, posterior leaflet prolapse in 257 patients, bileaflet prolapse in 25 patients, and commissural prolapse in 20 patients. Clefts that involved anterior or posterior leaflet were identified and closed in 21 patients. Neochordal replacement was used in 149 patients, including the loop-in-loop technique in 26 patients. Leaflet resection was performed in 145 patients, with quadrangular resection in 50 patients, triangular resection in 95 patients, and the sliding technique in 8 patients. The edge-to-edge technique was performed in 44 patients, commissuroplasty in 64 patients, and leaflet plication in 22 patients. C-shape annuloplasty bands were implanted in 133 patients and full rings in 257 patients. The mean prosthetic size was $29.1 \pm 2.1 \mathrm{~mm}$. After standardization according to body surface area, the mean indexed prosthetic size was $17.3 \pm 2.0 \mathrm{~mm} / \mathrm{m}^{2}$. The post bypass TEE showed that 3 patients had persistent systolic anterior motion and 5 patients had moderate residual MR. These 8 patients underwent reinstituted cardiopulmonary bypass and a successful second repair.

The operative mortality was $0 \%$. Postoperative morbidities included low cardiac output syndrome $(n=9)$, acute kidney failure $(\mathrm{n}=2)$, ventilation support $>72$ hours $(\mathrm{n}=5)$, reoperation for bleeding $(\mathrm{n}=6)$, and total atrioventricular block requiring pacemaker implantation $(\mathrm{n}=2)$. 
A total of 86 patients were discharged with antiarrhythmic drugs (amiodarone for 84 patients and propafenone for 2 patients). $\beta$-Blockers were prescribed for 213 patients $(54.6 \%)$ and calcium channel blockers for 30 patients $(7.7 \%)$.

Multivariate logistic models showed that cleft closure (odds ratio [OR], 6.81; 95\% confidence interval [CI], 1.45-31.92; $P=.015$ ), edge-to-edge technique (OR, 2.34; 95\% CI, 1.04-5.28; $P=.040$ ), ring annuloplasty (OR, 2.78; 95\% CI, 1.59-4.76; $P<.001)$, and indexed prosthetic size (OR, 0.78; 95\% CI, 0.68-0.89; $P<.001)$ were independent factors affecting PTMG.

\section{Surgical and Rhythm Outcomes}

Fifteen patients $(3.8 \%)$ were lost to follow-up. The median follow-up time was 46 months (ranging from 9 to 136 months). The 5-year all-cause mortality was 3.8\% ( $\mathrm{n}=6$, Figure E1). Among them, 1 patient died of endstage heart failure, 2 patients died of cerebrovascular events, and 3 patients died of noncardiac causes. Mitral valve reoperations were performed in 2 patients, because 1 patient had severe MR, and the other had mitral stenosis with MG of $9.7 \mathrm{~mm} \mathrm{Hg}$ before reoperation.

Rhythm outcomes are shown in Figure 1. Freedom from postoperative AF and atrial flutter was achieved in 274 patients $(73.1 \%)$. Early AF occurred in 85 patients $(22.7 \%)$, in whom paroxysmal $\mathrm{AF}$ was the major form of $\mathrm{AF}$ $(81.2 \%)$. The rate of late AF was $8.5 \%$ (32/375), and a nonparoxysmal AF predominance was observed in patients with late $\mathrm{AF}(78.1 \%)$. Moderate to severe MR was present in 4 of $32(12.5 \%)$ patients with late AF versus 18 of 343 $(5.2 \%)$ patients without late AF. This difference was not statistically significant $(P=.095)$. Ten patients underwent electrical cardioversion and 6 underwent $\geq 1$ transcatheter ablation procedures after 6 months after surgery. Pacemakers were implanted in 2 patients during follow-up.

Multivariate logistic analysis showed that preoperative left atrial diameter (OR, 1.03; 95\% CI, 1.00-1.05; $P=.025$ ) was the only important factor for early AF after mitral valve repair (Table E1). Age older than 65 years (OR, 2.16; 95\% CI, 1.01-5.33; $P=.039)$, PTMG $>3$ mm $\mathrm{Hg}$ (OR, 3.93; 95\% CI, 1.55-9.96; $P=.004$ ), and early AF (OR, 4.12; 95\% CI, 1.94-8.93; $P<.001)$ were identified as important risk factors for late AF (Table E2). Taking into account the maximum $\chi^{2}$ and the minimum $P$ values, the cutoff MG of $4.5 \mathrm{~mm} \mathrm{Hg}$ was identified as the best threshold to predict late AF after mitral valve repair $\left(\chi^{2}=40.704\right.$; $P<.001$; Table 3$)$. There was no significant difference in age between patients exhibiting MGs $<4.5 \mathrm{~mm} \mathrm{Hg}$ ( $\mathrm{n}=325$ ) and those with $\mathrm{MGs} \geq 4.5 \mathrm{~mm} \mathrm{Hg}$ ( $=50$; $P=.498$ ). The orifice areas of full annuloplasty rings are listed in Table 4. ${ }^{7,8}$ The indexed full ring orifice area

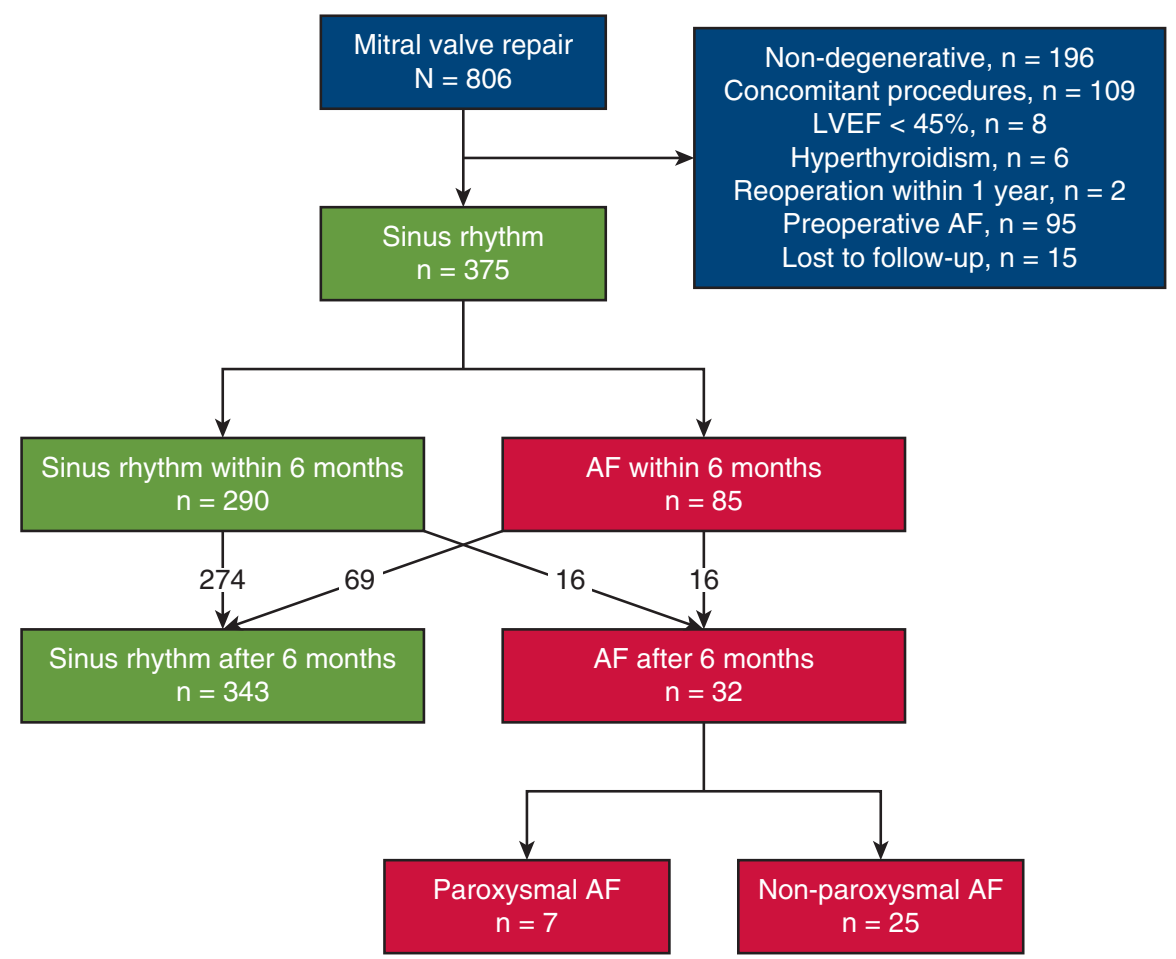

FIGURE 1. Rhythm outcomes for patients undergoing mitral valve repair without preoperative atrial fibrillation. $L V E F$, Left ventricular ejection fraction; $A F$, atrial fibrillation. 
TABLE 3. The minimum $P$ value approach for threshold of postoperative mean transmitral gradient for late atrial fibrillation

\begin{tabular}{lcc}
\hline Cutoff, $\mathbf{~ m m ~ H g}$ & $\chi^{\mathbf{2}}$ & $\boldsymbol{P}$ value \\
\hline 2 & 3.042 & .081 \\
2.5 & 9.568 & .002 \\
3 & 9.233 & .002 \\
3.5 & 8.728 & .003 \\
4 & 16.438 & $<.001$ \\
4.5 & $\mathbf{4 0 . 7 0 4}$ & $<.001$ \\
5 & 17.131 & $<.001$ \\
5.5 & 2.632 & .105 \\
6 & 0.763 & .383 \\
\hline
\end{tabular}

Data in bold indicate the optimum cutoff with the minimum $P$ value

$\leq 2 \mathrm{~cm}^{2} / \mathrm{m}^{2}$ was identified as the best threshold for predicting postoperative $\mathrm{MG} \geq 4.5 \mathrm{~mm} \mathrm{Hg}\left(\chi^{2}=25.984\right.$; $P<.001$; Table 5; Video 1).

\section{DISCUSSION}

Initiated by Carpentier's French correction in 1983, mitral valve repair has been accepted as the optimal surgery to treat degenerative MR by most surgeons. ${ }^{8,9}$ The concepts of degenerative MR repair have also been developing from leaflet resection to "respect rather than resect" approaches, aiming to preserve mitral valve area and facilitate cardiac reverse remodeling. ${ }^{10-12}$ Although previous studies have investigated the repair durability and clinical outcomes after repair of degenerative MR, less is known about the postoperative adverse effects, namely elevated PTMGs and occurrence of postoperative AF. Roberts and colleagues reported a high prevalence $(55.2 \%)$ of elevated PTMGs in patients who underwent mitral valve replacement after previous repair attempts. ${ }^{13}$ Furthermore, lower exercise capacity was observed in patients who underwent mitral valve repair for degenerative MR with MG $>3 \mathrm{~mm} \mathrm{Hg},{ }^{2}$ although the effect of surgical technique on PTMG and the potential relationship between PTMG and postoperative AF have not been verified. According to our results, using cleft closure, edge-to-edge technique, semirigid full rings, and smaller prosthetic size could lead to an elevated PTMG. Moreover, $\mathrm{MG} \geq 4.5 \mathrm{~mm} \mathrm{Hg}$ induced by an indexed full ring orifice area $<2 \mathrm{~cm}^{2} / \mathrm{m}^{2}$ was associated with a remarkably higher risk of late AF.

In this study, the mean postoperative MG of $3.1 \mathrm{~mm} \mathrm{Hg}$ was comparable with those in previous studies. ${ }^{14}$ Moreover, the mean prosthetic size of 29.1 , despite being seemingly smaller than those in previous studies, became acceptable after being indexed by the relatively small body surface areas. Our results were consistent with previous studies, in which full ring annuloplasty and smaller prosthetic size were associated with elevated PTMGs. ${ }^{15,16}$ In addition, the edge-to-edge technique might lead to a higher level of PTMG, consistent with previous work. ${ }^{17,18}$ However, Alfieri and colleagues, the pioneers introducing the concept of the edge-to-edge technique, did not report PTMG or rate of postoperative AF in their recent investigations of patients who underwent this procedure for degenerative MR. Instead, they simply stated that "clinically relevant mitral stenosis was never detected." ${ }^{19,20}$ Leaflet clefts, either on the anterior or posterior leaflet, were routinely closed with 5-0 polypropylene sutures. However, the cleft edges could have been fibrotic and thickened, especially in those with extension to the mitral annulus. $^{21}$ In this regard, direct cleft closure could result in poor leaflet mobility, smaller effective orifice area, and higher gradient. Other potential factors, including quadrangular leaflet resection, were of less significance in determining PTMG. We extrapolated that it was the small annuloplasty ring implanted after over-resection of the posterior leaflet rather than the technique itself that had a major effect on elevation of PTMG. Triangular resection and neochordal replacement might be more appropriate alternatives to allow for larger annuloplasty rings.

New-onset AF has been reported to be associated with long-term mortality after mitral valve surgery. ${ }^{22}$ However, the course of AF after mitral valve repair has been rarely discussed. In this study, nearly one-quarter of the cohort had early AF, whereas only 8.5\% had late AF. Moreover, PTMG was found to be associated with late AF, but not with early AF. These phenomena can be explained by an underlying mechanism, where an increase in left atrial afterload that undermines left atrial reverse remodeling might predispose to AF at a slow rate. On the contrary, early AF might be transient and more affected by the preoperative left atrial diameter, the surgery itself, and the perioperative management, which explains why paroxysmal AF was significantly more common in patients with early AF compared with those with late $\mathrm{AF}(81.2 \%$ vs $21.9 \%$; $P<.001)$.

In this study, the best MG threshold for predicting late AF was $4.5 \mathrm{~mm} \mathrm{Hg}$, and a total of 50 patients $(13.3 \%$ ) were beyond this threshold. However, it is noteworthy that MG $\geq 2.5 \mathrm{~mm} \mathrm{Hg}$ was the smallest cutoff that reached statistical

TABLE 4. Prosthetic orifice areas of full annuloplasty rings $(\mathrm{N}=257)$

\begin{tabular}{|c|c|c|c|c|c|c|}
\hline Brand & $26 \mathrm{~mm}$ & $28 \mathrm{~mm}$ & $30 \mathrm{~mm}$ & $32 \mathrm{~mm}$ & 34 mm & Reference \\
\hline Physio I, $\mathrm{cm}^{2}$ & $3.25(13)$ & $3.80(70)$ & $4.40(20)$ & $5.04(8)$ & $5.72(0)$ & 7 \\
\hline Memo-3D, $\mathrm{cm}^{2}$ & $2.78(6)$ & $3.28(27)$ & $3.78(51)$ & $4.39(41)$ & $4.98(21)$ & 8 \\
\hline
\end{tabular}

Data are presented as n (\%). Carpentier-Edwards Physio I ring from Edwards Lifesciences, Irving, Calif, and Sorin Memo-3D ring from Sorin Biomedica Cardio S.r.l., Saluggia, Italy. 
TABLE 5. The minimum $P$ value approach for threshold of indexed orifice area of full annuloplasty ring for postoperative mean transmitral gradient $\geq 4.5 \mathrm{~mm} \mathrm{Hg}$

\begin{tabular}{lrr}
\hline Cutoff, $\mathbf{~ c m}^{2} / \mathbf{m}^{2}$ & $\chi^{2}$ & $P$ value \\
\hline 1.75 & 0.252 & .617 \\
$\mathbf{2 . 0 0}$ & $\mathbf{2 5 . 9 8 4}$ & $<.001$ \\
2.25 & 4.742 & .029 \\
2.50 & 1.710 & .191 \\
2.75 & 2.430 & .119 \\
3.00 & 1.303 & .254 \\
3.25 & 0.769 & .381 \\
3.50 & 0.508 & .476 \\
\hline
\end{tabular}

Data in bold indicate the optimum cutoff with the minimum $P$ value.

significance, with a higher sensitivity but a much lower specificity compared with the threshold. In other words, absence of late AF cannot be guaranteed in patients with postoperative $\mathrm{MG}<4.5 \mathrm{~mm} \mathrm{Hg}$. Careful follow-up using Holter monitoring should be considered in patients with an elevated PTMG for early detection and management of AF.

According to our results and the data provided by manufacturers of annuloplasty rings, in patients with an average body surface area of $1.79 \mathrm{~m}^{2},{ }^{23}$ implantation of a $26-\mathrm{mm}$ Physio I ring (Edwards) or a $28 \mathrm{~mm}$ Memo-3D ring (Sorin Biomedica Cardio S.r.l.) might lead to an $\mathrm{MG} \geq 4.5 \mathrm{~mm} \mathrm{Hg}$ and thereby a higher risk of late AF. Furthermore, a 28- to 30-mm Physio I ring (Edwards) and a 30- to 32-mm Memo-3D ring (Sorin Biomedica Cardio S.r.l.) might fail to preserve adequate orifice area, if a cleft is to be closed or the edge-to-edge technique is to be used. Future studies are warranted to investigate the dynamic balance between leaflet repair techniques and optimal prosthetic sizes.

This study is subject to the limitations inherent in retrospective, single-center data studies. Patients with previously undetected paroxysmal AF might not have been effectively excluded from the study, and parameters reflecting atrial

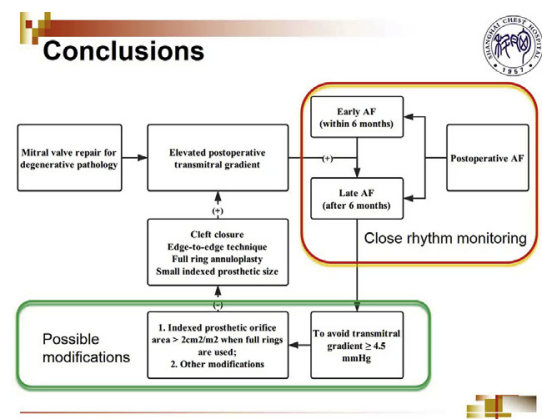

VIDEO 1. The first author Dr Ma presenting the background and clinical relevance of the study. Video available at: https://www.jtcvs.org/article/ S0022-5223(18)32470-X/fulltext. volume and function have not been routinely performed at our institution over the past decade. Furthermore, despite the moderate size of the cohort, the incidence of late AF was relatively low, which might undermine the power of statistical analysis. To address this, intergroup $\chi^{2}$ comparisons using different MG cutoffs were performed, and were favorably consistent with the results of the multivariate models. Finally, the measurement of PTMG might be biased by patients' heart rate and volume status. Nevertheless, our observations provided a clear course of heart rhythm outcomes after mitral valve repair for degenerative MR and validated the relationship between late AF and PTMG.

\section{CONCLUSIONS}

Patients who undergo mitral valve repair for degenerative mitral insufficiency might benefit from modifications of the existing leaflet repair and annuloplasty techniques for a lower PTMG level, which is associated with a decreased incidence of late AF during follow-up. Calculating the minimum ring size on the basis of indexed prosthetic orifice area may be considered before surgery.

\section{Conflict of Interest Statement}

Authors have nothing to disclose with regard to commercial support.

We thank Mr Xinyu Ma, MS, for statistical consulting.

\section{References}

1. Nishimura RA, Otto CM, Bonow RO, Carabello BA, Erwin JP III, Guyton RA, et al. 2014 AHA/ACC guideline for the management of patients with valvular heart disease: a report of the American College of Cardiology/American Heart Association Task Force on Practice Guidelines. J Thorac Cardiovasc Surg. 2014;148:e1-132.

2. Chan KL, Chen SY, Chan V, Hay K, Mesana T, Lam BK. Functional significance of elevated mitral gradients after repair for degenerative mitral regurgitation. Circ Cardiovasc Imaging. 2013;6:1041-7.

3. Ma W, Chen J, Zhang W, Wu W, Ye W, Shi W, et al. Triangular resection versus neochordal replacement for posterior leaflet prolapse: a morphological assessment. Interact Cardiovasc Thorac Surg. 2018;26:54-9.

4. Varghese R, Anyanwu AC, Itagaki S, Milla F, Castillo J, Adams DH. Management of systolic anterior motion after mitral valve repair: an algorithm. J Thorac Cardiovasc Surg. 2012;143:S2-7.

5. January CT, Wann LS, Alpert JS, Calkins H, Cigarroa JE, Cleveland JC Jr, et al. 2014 AHA/ACC/HRS guideline for the management of patients with atrial fibrillation: a report of the American College of Cardiology/American Heart Association Task Force on Practice Guidelines and the Heart Rhythm Society. J Am Coll Cardiol. 2014;64:e1-76.

6. Mazumdar M, Glassman JR. Categorizing a prognostic variable: review of methods, code for easy implementation and applications to decision-making about cancer treatments. Stat Med. 2000;19:113-32.

7. Carpentier-Edwards Physio Annuloplasty Ring. Available at: http://ht.edwards. com/resourcegallery/products/rings/pdfs/2188update.pdf. Accessed March 28, 2018.

8. Memo-3D Annuloplasty Ring. Available at: http://www.livanova.sorin.com/file/ download-7820.action. Accessed March 28, 2018.

9. Carpentier A. Cardiac valve surgery-the "French correction" J Thorac Cardiovasc Surg. 1983;863:23-37.

10. Mazine A, Friedrich JO, Nedadur R, Verma S, Ouzounian M, Jüni P, et al. Systematic review and meta-analysis of chordal replacement versus leaflet resection 
for posterior mitral leaflet prolapse. J Thorac Cardiovasc Surg. 2018;155: 120-8.e10.

11. Lawrie GM, Earle EA, Earle N. Intermediate-term results of a nonresectional dynamic repair technique in 662 patients with mitral valve prolapse and mitral regurgitation. J Thorac Cardiovasc Surg. 2011;141:368-76.

12. Lawrie GM, Zoghbi W, Little S, Shah D, Ben-Zekry Z, Earle N, et al. One hundred percent reparability of degenerative mitral regurgitation: intermediate-term results of a dynamic engineered approach. Ann Thorac Surg. 2016;101:576-83; discussion 583-4.

13. Roberts WC, Moore M, Ko JM, Hamman BL. Mitral Valve Replacement After Failed Mitral Ring Insertion With or Without Leaflet/Chordal Repair for Pure Mitral Regurgitation. Am J Cardiol. 2016;117:1790-807.

14. Murashita T, Greason KL, Suri RM, Daly RC, Joyce LD, Stulak JM, et al. Mitral valve gradient after valve repair of degenerative regurgitation with restrictive annuloplasty. J Thorac Cardiovasc Surg. 2016;151:106-9.

15. Mesana TG, Lam BK, Chan V, Chen K, Ruel M, Chan K. Clinical evaluation of functional mitral stenosis after mitral valve repair for degenerative disease: potential affect on surgical strategy. J Thorac Cardiovasc Surg. 2013;146: 1418-23; discussion: 1423-5.

16. Witschey WR, Zhang D, Contijoch F, McGarvey JR, Lee M, Takebayashi S, et al. The influence of mitral annuloplasty on left ventricular flow dynamics. Ann Thorac Surg. 2015;100:114-21.

17. da Rocha E, Silva JG, Spampinato R, Misfeld M, Seeburger J, Pfanmüller B, et al. Barlow's mitral valve disease: a comparison of neochordal (loop) and edge-toedge (alfieri) minimally invasive repair techniques. Ann Thorac Surg. 2015; 100:2127-33; discussion: 2133-5.
18. Chen X, Turley RS, Andersen ND, Desai BS, Glower DD. Minimally invasive edge-to-edge mitral repair with or without artificial chordae. Ann Thorac Surg. 2013;95:1347-53.

19. De Bonis M, Lapenna E, Maisano F, Barili F, La Canna G, Buzzatti N et al. Long-term results ( $\leq 18$ years) of the edge-to-edge mitral valve repair without annuloplasty in degenerative mitral regurgitation: implications for the percutaneous approach. Circulation. 2014;130(11 Suppl 1): S19-24.

20. De Bonis M, Lapenna E, Taramasso M, La Canna G, Buzzatti N, Pappalardo F, et al. Very long-term durability of the edge-to-edge repair for isolated anterior mitral leaflet prolapse: up to 21 years of clinical and echocardiographic results. J Thorac Cardiovasc Surg. 2014;148:2027-32.

21. Ring L, Rana BS, Ho SY, Wells FC. The prevalence and impact of deep clefts in the mitral leaflets in mitral valve prolapse. Eur Heart J Cardiovasc Imaging. 2013; 14:595-602.

22. Bramer S, van Straten AH, Soliman Hamad MA, van den Broek KC Maessen JG, Berreklouw E. New-onset postoperative atrial fibrillation predicts late mortality after mitral valve surgery. Ann Thorac Surg. 2011;92: 2091-6.

23. Sacco JJ, Botten J, Macbeth F, Bagust A, Clark P. The average body surface area of adult cancer patients in the UK: a multicentre retrospective study. PLoS One 2010;5:e8933.

Key Words: mitral valve repair, degenerative mitral regurgitation, atrial fibrillation

Readers who found these articles interesting may also like to read the following papers found in recent and future issues of our sister publications, Seminars in Thoracic and Cardiovascular Surgery and Operative Techniques in Thoracic and Cardiovascular Surgery!

\section{Adult: Mitral Valve}

ORIGINAL SUBMISSION: Is Surgical or Catheter-based Interventions an Option After an Unsuccessful Mitral Clip? Felix Kreidel. Semin Thoracic Surg 2018: 152-157.

Editorial Commentary: With Every New Technology Comes a Learning Curve. Saina Attaran. Semin Thoracic Surg 2018: 158-159.

ORIGINAL SUBMISSION: Tiara Valve Implantation in a Patient With Previously Implanted Mono-disk Mechanical Aortic Prosthesis. Enrico Ferrari. Semin Thoracic Surg 2018: 160-163.

Editorial Commentary: Connubial Bliss or Distress? Transcatheter Mitral Valve Implantation With Mechanical Aortic Prostheses. Mohamad Alkhouli. Semin Thoracic Surg 2018: 164-165.

CASE REPORT: Minimally Invasive SAPIEN in Mitral Annular Calcification Following Transcatheter Aortic Valve Replacement: Feasibility and Lessons Learned. Tom C. Nguyen. Semin Thoracic Surg 2018: In press. 


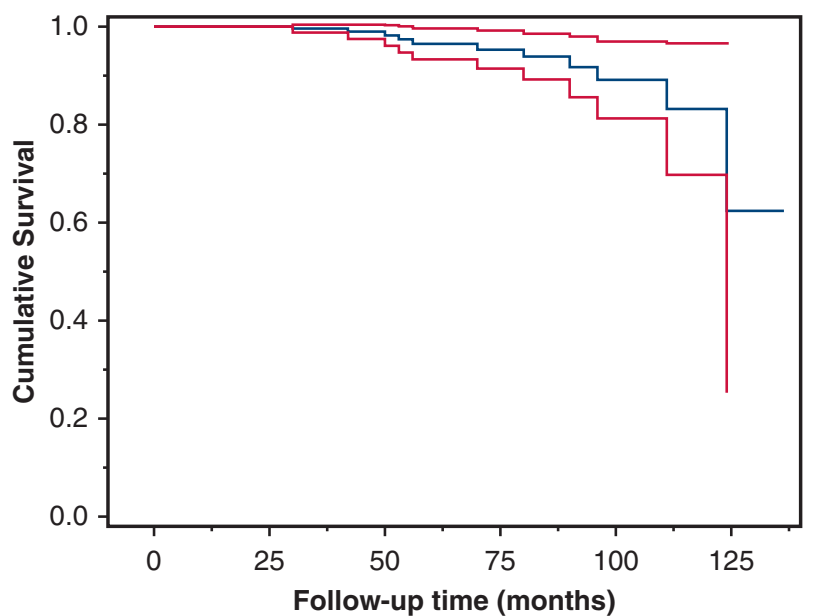

Patients at risk

390

327

129

73

29

5

FIGURE E1. The Kaplan-Meier survival curve (blue line) and its $95 \%$ confidence limits (red lines). 
TABLE E1. Variable selection in the stepwise logistic model for investigating risk factors for early AF

\begin{tabular}{|c|c|c|c|c|}
\hline \multicolumn{2}{|l|}{ Step 0 variables } & \multicolumn{3}{|c|}{ Variables in the final model } \\
\hline Variables & $P$ value & Variable & OR $(95 \%$ CI $)$ & $P$ value \\
\hline Age older than $65 \mathrm{y}$ & .304 & & & \\
\hline Male sex & .472 & & & \\
\hline Surgeon & .885 & & & \\
\hline Hypertension & .161 & & & \\
\hline Diabetes mellitus & .942 & & & \\
\hline Coronary artery disease & .372 & & & \\
\hline Chronic obstructive pulmonary disease & .254 & & & \\
\hline Chronic kidney disease & .599 & & & \\
\hline History of stroke & .254 & & & \\
\hline NYHA functional class III to IV & .235 & & & \\
\hline Left atrial diameter & .025 & Left atrial diameter & $1.03(1.00-1.05)$ & .025 \\
\hline Left ventricular end-systolic diameter & .927 & & & \\
\hline Left ventricular end-diastolic diameter & .601 & & & \\
\hline LVEF & .297 & & & \\
\hline Minimally invasive & .083 & & & \\
\hline Location of degenerative lesion & .266 & & & \\
\hline Cleft closure & .775 & & & \\
\hline Leaflet resection & .454 & & & \\
\hline Quadrangular resection & .880 & & & \\
\hline Sliding technique & .104 & & & \\
\hline Neochordal replacement & .144 & & & \\
\hline Loop-in-loop technique & .122 & & & \\
\hline Edge-to-edge technique & .162 & & & \\
\hline Commissuroplasty & .220 & & & \\
\hline Leaflet plication & .836 & & & \\
\hline Full annuloplasty ring & .097 & & & \\
\hline Indexed prosthetic size & .266 & & & \\
\hline Tricuspid annuloplasty & .390 & & & \\
\hline Postoperative left atrial diameter & .458 & & & \\
\hline Postoperative left ventricular end-systolic diameter & .746 & & & \\
\hline Postoperative left ventricular end-diastolic diameter & .262 & & & \\
\hline Postoperative LVEF & .343 & & & \\
\hline Postoperative MR & .852 & & & \\
\hline PTMG & .283 & & & \\
\hline
\end{tabular}


TABLE E2. Variable selection in the stepwise logistic model for investigating risk factors for late AF

\begin{tabular}{|c|c|c|c|c|}
\hline \multicolumn{2}{|l|}{ Step 0 variables } & \multicolumn{3}{|c|}{ Variables in the final model } \\
\hline Variable & $P$ value & Variable & OR $(95 \%$ CI $)$ & $P$ value \\
\hline Age older than $65 \mathrm{y}$ & .015 & Age older than $65 y$ & $2.16(1.01-5.33)$ & .039 \\
\hline Male sex & .221 & & & \\
\hline Surgeon & .799 & & & \\
\hline Hypertension & .126 & & & \\
\hline Diabetes mellitus & .380 & & & \\
\hline Coronary artery disease & .467 & & & \\
\hline Chronic obstructive pulmonary disease & .753 & & & \\
\hline Chronic kidney disease & .753 & & & \\
\hline History of stroke & .787 & & & \\
\hline NYHA functional class III to IV & .810 & & & \\
\hline Left atrial diameter & .347 & & & \\
\hline Left ventricular end-systolic diameter & .492 & & & \\
\hline Left ventricular end-diastolic diameter & .336 & & & \\
\hline LVEF & .183 & & & \\
\hline Minimally invasive & .654 & & & \\
\hline Location of degenerative lesion & .312 & & & \\
\hline Cleft closure & .201 & & & \\
\hline Leaflet resection & .967 & & & \\
\hline Quadrangular resection & .657 & & & \\
\hline Sliding technique & .519 & & & \\
\hline Neochordal replacement & 1.000 & & & \\
\hline Loop-in-loop technique & .519 & & & \\
\hline Edge-to-edge technique & .167 & & & \\
\hline Commissuroplasty & .900 & & & \\
\hline Leaflet plication & .467 & & & \\
\hline Full annuloplasty ring & .123 & & & \\
\hline Indexed prosthetic size & .095 & & & \\
\hline Tricuspid annuloplasty & .330 & & & \\
\hline Postoperative left atrial diameter & .278 & & & \\
\hline Postoperative left ventricular end-systolic diameter & .454 & & & \\
\hline Postoperative left ventricular end-diastolic diameter & .385 & & & \\
\hline Postoperative LVEF & .555 & & & \\
\hline Postoperative MR & .607 & & & \\
\hline PTMG $>3 \mathrm{~mm} \mathrm{Hg}$ & $<.001$ & PTMG $>3 \mathrm{~mm} \mathrm{Hg}$ & $3.93(1.55-9.96)$ & .004 \\
\hline Early AF & $<.001$ & Early AF & $4.12(1.94-8.93)$ & $<.001$ \\
\hline$\beta$-Blocker & .099 & & & \\
\hline ACEI/ARB & .388 & & & \\
\hline
\end{tabular}

